American Journal of Infectious Diseases 3 (4): 184-190, 2007

ISSN 1553-6203

(C) 2007 Science Publications

\title{
Medical Consequences of Drug Abuse and Co-occurring Infections: A Brief Review
}

\author{
Jag H. Khalsa, \\ National Institute on Drug Abuse, \\ National Institutes of Health, Bethesda, Maryland, USA
}

\begin{abstract}
Today substance abuse remains one of the major problems in the world with millions of people abusing legal and illegal drugs. In addition, almost one-third of the world population of 6.7 billion people may also be infected with one or more infections. Both drugs of abuse and infections are associated with enormous burden of social, economic and health consequences. This paper briefly discusses a few medical consequences of drugs of abuse and infections such as human immunodeficiency virus and hepatitis $C$ virus. Research is encouraged to study interactions between infections, drugs of abuse, and underlying pathophysiologic and molecular/genetic mechanisms of these interactions.
\end{abstract}

Key words: Medical Consequences, Drug Abuse, HIV/AIDS

\section{INTRODUCTION}

Today substance abuse and infections are two of the major problems in the world with an estimated 200 million people abusing illegal drugs regularly ${ }^{[1]}$ and an estimated one-third of the world's population of 6.7 billion people living with one or more infections ${ }^{2}$. In the US alone, according to the 2005 National Survey on Drug Use and Health ${ }^{[3]}$, about 112 million Americans 12 years and older $(46 \%)$ used at least one illicit drug (e.g., amphetamines, cocaine, heroin, or marijuana) in their lifetime. An estimated 20 million people are current users of an illicit drug. Unfortunately no data are available on the nature and extent of drug abuse in India. There are an estimated 40 million people in the world living with human immunodeficiency virus (HIV) infection, about 200 million infected with hepatitis $\mathrm{C}$ virus (HCV), 2 billion people infected with tuberculosis (TB) and many more millions with various other bacterial and viral infections ${ }^{[4]}$. An estimated 1 million people infected with HIV, and 4 million people infected with HCV live in the US. Both infections are prevalent among substance abusers. Injection drug use (IDU) directly and indirectly accounts for more than one-third $(36 \%)$ of AIDS cases; of the 42,156 new cases of AIDS reported in the US in 2000, 11,635 $(28 \%)$ were associated with injection drug use ${ }^{[5]}$. About $80 \%$ to $90 \%$ of HIV positive IDUs may also infected with HCV (5). In addition to HIV and HCV, other viral and bacterial infections such as mycobacterial leading to tuberculosis (TB), sexuallytransmitted infections, streptococcal and staphylococcal infections (leading to endocarditis) and others have all been reported in drug abusers ${ }^{[6]}$.
Sociopolitical, economic, and health costs to the society from substance abuse and infections are enormous. Legal and illegal substance abuse alone costs the American society an estimated one-half a trillion dollars annually ${ }^{[8]}$, while diabetes and cancer cost an estimated $\$ 132$ billion ${ }^{[9]}$ and $\$ 263$ billion $^{[10]}$, respectively. Both drugs of abuse and infections such as HIV and HCV affect almost every physiological/biochemical system in the body. Thus, health effects may range between neuropsychiatric complications, anxiety and depressive disorders, cardiovascular complications, impairment of immune system, metabolic/endocrine disorders (lipodystrophy), and hepatic failure, to name a few. Because the subject of health consequences of drugs of abuse and infections is very wide and could not be covered in a minisymposium at the Drug Abuse and HIV/AIDS conference, held for the first time in Kerala, India, a brief review of the current status of research on medical consequences of drug abuse and infections supported by the US National Institute on Drug Abuse, a part of the National Institutes of Health, is being presented herein.

Medical Consequences: In general, stimulants such as cocaine and methamphetamine ('met', 'speed', or 'ice') increase the heart rate while constricting the blood vessels; in susceptible individuals, these two actions together set the stage for cardiac arrhythmias and strokes ${ }^{11}$. Methamphetamine also causes serious hyperthermia, increases wakefulness and physical activity, creating the potential for a combination of activity and overheating that leads to convulsions and dangerous, sometimes lethal elevation of body temperature $^{[11]}$. Cocaine use decreases the blood flow to 
the brain, increases the heart rate, and elevates the blood components that promote clotting-effects that can lead to stroke or heart attack even in those not otherwise at risk for these serious cardiovascular events ${ }^{[11]}$. NIDA-funded research also shows that chronic cocaine use is associated with left ventricular dysfunction $^{[12]}$ and increased calcium deposits in the coronaries $^{[13]}$ of HIV infected African-Americans, and that its use may also facilitate the entry of HIV into brain cells ${ }^{[14]}$, possibly leading to HIV encephalopathy. The club drug methylene-dioxy-methamphetamine (MDMA), also known as 'ecstasy', which many users mistakenly believe to be safe, may cause malignant hyperthermia, permanent kidney damage, and death. In non-human primate studies, MDMA also damages serotonin nerve fibers in the brain. Heroin can cause a life-threatening kidney renal condition called focal glomerulosclerosis ${ }^{[15]}$. Opiate (heroin) use is associated with consequences ranging from nausea and constipation to renal, dental, and orofacial complications. PCP (phencyclidine, or 'angel dust') decreases heart rate and blood pressure, triggers violent aggression, and may trigger muscle contractions strong enough to break a bone ${ }^{[11]}$. Marijuana, the most abused illicit drug in the world and often perceived by many as an innocuous drug, is associated with consequences ranging from memory, cognitive and motor problems in young and adult individuals to possible lung cancer in chronic marijuana smokers, although the latter have not been confirmed. The NIDA-published special supplement reviewed the most up-to-date research on clinical consequences of marijuana ${ }^{[16]}$. Injecting drug use and drug use associated impulsive sexual activity further promotes acquisition and transmission of sexually-transmitted and blood-borne infections including life-threatening endocarditis, viral hepatitis, HIV/AIDS and STDs.

Human Immunodeficiency Virus (HIV): HIV, a blood-borne retrovirus that infects CD4 T-cell lymphocytes and macrophages, causes profound immunosuppression that eventually develops into fullblown AIDS. HIV infection results into flu-like syndrome consisting of fever, fatigue, pharyngitis, decreased CD4 T-cell lymphocytes, increased viral load, and finally progression to AIDS, the latter depending on factors such as the use of illicit drugs, opportunistic infections (OI) prophylaxis, and antiretroviral therapy. It may be noted that in about $5 \%$ of the individuals, the disease does not progress to AIDS. These individuals are known as long-term nonprogressors and have a low viral load burden, strong virus-specific immune responses, and moderate viral attenuation $^{[17]}$. Since the virus may infect almost every organ, the effects of HIV infection may also range from immunosuppression to wasting and other metabolic/endocrine disorders, cardiomyopathy, nephropathy, neuroAIDS, and many other health consequences. The course of HIV infection and the development of AIDS are further complicated by metabolic and endocrine abnormalities secondary to the direct toxic effects of HIV, other OIs such as HCV, TB, STIs, neoplasms, and complications of drugs used during treatment.

Hepatitis C Virus: Hepatitis C virus is another bloodborne pathogen that is easily transmitted through contaminated drug injection paraphernalia. Approximately $40 \%$ of chronic liver disease is related to $\mathrm{HCV}$ infection, making it the most common cause of chronic liver disease and the major reason for liver transplantation performed in the US. An estimated 8,000 to 10,000 persons with HCV-related liver cancer may die each year ${ }^{[18]}$. Because HIV and HCV have common transmission pathways, coinfection is quite frequent, with prevalence as high as $90 \%$ of HIVinfected IDUs also infected with $\mathrm{HCV}$ in some countries in Central, South, and Southeast Asia and Eastern Europe ${ }^{[19,20,21]}, 50$ to $75 \%$ in countries in Southeast Asia ${ }^{[22]}$; $33 \%$ in St. Petersburg, Russia ${ }^{23}$; and 50 to $55 \%$ in Australia ${ }^{[24]}$. Recent reports from India show that there are an estimated 5.6 million people living with HIV infection ${ }^{[25]}$; no numbers are available on co-infections with HIV/HCV.

During the acute phase of HCV infection, which is difficult to diagnose and which may last about six weeks, symptoms may include malaise, nausea, right upper quadrant pain, and jaundice. About 75 to $85 \%$ of these patients may become chronically infected. During the chronic phase of HCV infection, which may last several decades, symptoms may include nausea, anorexia, myalgia, and arthralgia, with fatigue being the most common complaint ${ }^{[26]}$. Alcohol use and advanced age accelerate the disease progression of $\mathrm{HCV}$ infection, especially among men. Approximately $20 \%$ of these chronic patients will develop liver cirrhosis within 20 years, and 1 to $5 \%$ of them will die from $\mathrm{HCV}$-related liver cancer. HCV infection is also associated with the development of diabetes mellitus among IDUs ${ }^{[27]}$. Dual infections with HIV and HCV also occur from common routes of transmission and these individuals are at risk of developing chronic liver inflammation and hepatic cancer or liver failure requiring transplantation. Hepatic injury seems to occur in dual infections through the induction of a novel signaling pathway, that is cooperatively activated by specialized protein molecules, known as HCV E2 and HIV gp120, thereby providing a rationale for therapeutic interventions ${ }^{[28]}$. NIDA supports a wide spectrum of research on epidemiology, natural history, 
underlying pathogenesis, prevention and treatment of HIV/HCV co-infections among drug abusers.

Tuberculosis: Among all the infectious diseases that affect humans, TB remains the deadliest contagious disease caused by Mycobacterium tuberculosis, a pathogenic bacterium that establishes its infection mainly in the lungs. An estimated 2 billion people in the world are living with TB and an estimated 2 million die each year. India has the largest number of TB cases with an estimated 1000 people dying each day ${ }^{[29]}$. In the United States, a total of 13,767 tuberculosis (TB) cases (4.6 per 100,000 population) were reported in 2006 with rates of TB incidence declining from $7.3 \%$ per year during 1993--2000 to 3.8\% during 2000--2006. Progression of TB is accelerated by a number of factors such as co-occurring infections, e.g., HIV, drugs of abuse, poor nutrition, and many others. HIV contributes to the TB pandemic because HIV-induced immune suppression increases the likelihood of rapid progression from primary $\mathrm{TB}$ infection to active $\mathrm{TB}$ disease. But from 2005 to 2006, the percentage of TB cases with HIV infection has also decreased from $13.0 \%$ to $12.4 \%{ }^{[30]}$. Drug users are at particularly high risk of TB infection with reported high rates of active TB among drug users ${ }^{[31,32]}$. TB infection can be effectively treated with currently available drugs including isoniazid, rifampin, streptomycin, ethambutol, pyrazinamide, ciprofloxacin, and ofloxacin. On the other hand, although the rates of TB incidence have declined in the US and elsewhere, the emergence of multi-drug resistant strain of mycobacterium (MDR) and extremely drug resistant (XDR) strain of the bacterium is of major concern. A total of 124 cases of multidrug-resistant TB (MDR TB) were reported in 2005, mostly in foreign-born individuals. Thus, vigorous efforts are underway to find better diagnostic tests/tools and to design/develop effective intervention, prevention and treatment modalities.

Nutrition also might play an important role in HIV disease progression. Research suggests that drug abusers with inadequate nutrition, particularly with suboptimal levels of anti-oxidant micronutrients such as selenium and zinc, may be at high risk of mortality if they are also co-infected with $\mathrm{HIV}^{[33]}$. NIDA-supported clinical trials are in progress to determine if supplementation with selenium, zinc, and other antioxidant micronutrients would slow the progression of HIV/AIDS disease. Daily supplementation with $200 \mathrm{ug}$ of selenium increases the CD4 $\mathrm{T}$ cell lymphocyte counts and decreases the viral load in HIV-infected patients $^{[34]}$. This type of research would have worldwide implications, such that, in underdeveloped countries where poor people cannot afford expensive antiretroviral therapy, they could benefit from inexpensive treatment modality to slow disease progression and improve the quality of life.

Both viral infections of Hepatitis $\mathrm{C}$ and HIV continue to spread in an epidemic fashion among vulnerable populations, including those with mental illness and drug addiction. Drug abuse remains the major vector in the acquisition and transmission of both infections with serious consequences ${ }^{[35]}$ including psychiatric disorders that in turn may further maintain Hepatitis C epidemic. Major depression, severe mental illness, and personality disorders lead to high risk behaviors for Hepatitis $\mathrm{C}$, and yet these disorders may be made worse by Hepatitis $\mathrm{C}$ and the medications used to treat $\mathrm{it}^{[36]}$. Major depression is a common comorbidity in patients with Hepatitis C infection ${ }^{[37]}$.

Hepatitis $\mathrm{C}$ patients also have poorer outcomes if they are ongoing drug users ${ }^{[26]}$. Alcohol is risk factor for Hepatitis $\mathrm{C}$ infection, probably through the indirect mechanisms, but it is also associated with more rapid progression of $\mathrm{HCV}$ and more frequent development of liver cancer ${ }^{[38]}$. Despite these ominous problems, patients with substance use disorders can be successfully treated for HIV and Hepatitis C if the clinical resources needed for treatment are provided ${ }^{[39-}$ 41]

Mental illness including anxiety disorders, major depression and bipolar disorder are associated with substance use, increased high risk sexual behavior, and with other self destructive behaviors ${ }^{[42]}$. Depression may also increase the risk of acquiring HIV and HCV infections and may interfere with treatment. On the other hand, depression may also be caused by antiretroviral medications such as efaviren $z^{[43]}$ and interferon used in the treatment of $\mathrm{HCV}$ infection. Although ribavirin, also used in the treatment of $\mathrm{HCV}$ infection, may worsen depression, interferon is associated with severe CNS side effects such as frank psychosis, which may persist after discontinuation. Other common symptoms are: apathy, fatigue, irritability, sleep disturbance (both hypersomnia and insomnia), confusion, inattention, anorexia, sexual dysfunction, and suicidal feelings ${ }^{[44]}$. Treatment with antidepressants is effective but does not favor any one class of medications. Thus, treatment agents need to be developed that are safe (devoid of severe side effects) and effective against single or dual infections of HIV and/or HCV in drug abusing populations.

Drug Interactions: Pharmacokinetic and pharmacodynamic interactions between medications used in the treatment of infections and addiction should be considered when designing treatment protocols for drug addicts. Despite the large number of drug abusers with HIV disease, HAART is frequently underutilized in this population because of the difficulties 
experienced in obtaining adherence adequate to maintain viral suppression ${ }^{[45-48]}$. Provision of drug abuse treatment is often a key component to successful treatment of HIV disease in this population. Multiple studies have shown that drug interactions between antiretrovirals and other medications having effects on cytochrome p450 enzymes can lead to altered therapeutic profiles, toxicities and side effects with drugs used for the treatment of HIV ${ }^{[49]}$. This, in turn, may decrease adherence to medical treatment for HIV/AIDS $^{[50]}$ leading to lack of efficacy of HIV treatment, development of viral resistance to currently available therapies, and increased illicit drug abuse. Because opioid pharmacotherapies are the treatment of choice for opioid-addicted individuals with HIV/AIDS, it is essential that clinicians have a thorough understanding of possible drug interactions between opioids, specifically methadone and buprenorphine, and antiretroviral therapies in order to enhance the clinical care of drug users with HIV/AIDS.

The earlier studies showed interactions between methadone and antiretrovirals. For example, the plasma levels of zidovudine increased by $41 \%$ when used in the treatment of AIDS in methadone maintained patients ${ }^{[51]}$ but not in buprenorphine maintained patients ${ }^{[52]}$. On the other hand, patients treated with protease inhibitors like lopinavir/ritonavir or non-nucleoside reverse transcriptase inhibitor (NNRTI) efavirenz, the plasma levels of methadone decreased resulting in opiate withdrawal ${ }^{[33-55]}$. By contrast, no clinically significant interactions occurred between ARVs and buprenorphine ${ }^{[53,54]}$. Data show that now buprenorphine may offer an alternative opioid therapy that could help to improve adherence to antiretroviral medications prescribed for the treatment of HIV disease in opioiddependent patients.

New Pharmacotherapeutics on the Horizon: Since the discovery of the first case of HIV, many effective medications including highly active antiretroviral therapy (HAART) and the newest drug, Fusion, have been developed for the treatment of HIV/AIDS. On the other hand, only pegylated interferon alfa and ribavirin are available for the treatment of hepatitis $\mathrm{C}$ infection. However, new drug therapies to treat hepatitis C (HCV) and HIV infection are being developed with improved understanding of the molecular structures of the viruses themselves, the pathogenesis of infection and the specific immune responses needed to eradicate or control these infections. Interferon and ribavirin based therapies will continue to be a component of $\mathrm{HCV}$ therapy for the near future combined with other novel compounds directed at targets of viral replication, immunomodulation or cell entry. The goals of antiHCV therapy are viral eradication for various genotypes, prevention of hepatic morbidity such as hepatocellular carcinoma and cirrhosis. Future antiretroviral therapies for HIV will include agents that focus on new classes of inhibitors of viral replication and cell binding. The new treatment choices in HIV will need to ensure effective and durable viral suppression especially against highly resistant virus strains, regimen tolerability and improved toxicity

Targets for Hepatitis C Infection: A number of new agents are in development for the treatment of HCV infection since the goals of ARV therapy are to limit viral replication, prevent new infection, and enhance clearance of infected cells. Currently, drug candidates in various stages of development are: (i) A derivative of interferon, such as albuferon ${ }^{[56,57]}$, and derivatives of ribavirin such as viramadine or taibivirin); (ii) Drugs directed against components of HCV genome (e.g., protease inhibitors such as telaprevir or VX-950; SCH 503034; nucleoside HCV RNA polymerase inhibitors such as valopicitabine (NM283), R1626 and HCV796); and (iii) Immune modulators including vaccines (such as isatoribine, a Toll-like receptor agonist that stimulates the natural immune response to a pathogen such as hepatitis C; and CPG 10101, a TLR9 receptor agonist that acts as an antiviral and Th1 immune enhancer ${ }^{[58,59]}$.

Targets for HIV Infection: Currently there are at least 26 FDA approved drugs for the treatment of HIV/AIDS and these belong to four classes of drugs and include: nucleoside reverse transcriptase inhibitors (NRTI's), non-nucleoside reverse transcriptase inhibitors (NNRTIs), protease inhibitors (PIs) and one fusion inhibitor (FI). New formulations of drugs are available to reduce pill burden such as a single pill daily (emcitritabine/tenofovir/efavirenz) or newer agents in a class that may suppress resistant virus strains e.g. darunavir, a PI with excellent virologic activity against HIV with multiple resistance mutations ${ }^{[60]}$.

Newer therapeutic agents in development include the following: (1) Entry inhibitors such as CXCR4 (AMD 070) or the CCR5 receptor blockers (maraviroc and vicriviroc); (2) integrase inhibitors such as MK0518 and GS-9137 and (3) maturation inhibitor such as PA- $457^{61}$ are in various stages of development. These new agents, singly or in combination to overcome acquired resistance development, may provide options for both naïve and treatment experienced HIV infected patients. In the absence of preventive or therapeutic vaccines for hepatitis $\mathrm{C}$ or HIV, the intersections of human behavior, genetics and pharmacology will provide ongoing challenges to the management of infected persons. 


\section{CONCLUSION}

In summary, both drug abuse and single or dual infections of HIV and HCV are associated with a wide variety of serious medical and health consequences. Although treatment of drug addiction and infections of HIV and/or HCV is complex, it is achievable with integrated programs of health care for dually infected drug addicts. The problem of drug interactions that appeared between HIV antiretrovirals and methadone seems to be less with the newly approved buprenorphine. Future research will show whether similar interactions would occur between buprenorphine or methadone and newer drugs that are being developed for the treatment of HIV and HCV. It is also anticipated that the newer antiretroviral medications would have lesser neuropsychiatric complications or pharmacokinetic interactions.

\section{ACKNOWLEDGMENTS}

Author is grateful to Dr. Glenn Triesmann of Johns Hopkins, Dr. Elinore McCance-Katz of Virginia Commonwealth University, and Dr. Ellen Tedaldi of Temple University for valuable information neuropsychiatric complications of drug abuse and infections, drug interactions, and new drugs in development.

\section{REFERENCES:}

1. United Nations Office on Drugs and Crime. World Drug Report 2006. United Nations Office on Drugs and Crime, ISBN 92-1-148214-7, Vol 1,2, 2006.

2. United Nations AIDS (UNAIDS). 2006 Report on the global epidemic of AIDS: Executive Summary; UNAIDS/06-20E, English, ISBN 929-1735-116, Joint United Nations Programme on HIV/AIDS/WHO, 2006.

3. Substance Abuse and Mental Health Services Administration (SAMHSA). Overview of Findings from the 2005 National Survey on Drug Abuse and Health, Office of Applied Studies, NSDUH Series H-24, DHHS Publications, Rockville, MD, 2006.

4. World Health Organization 2006 Fact Sheet, WHO/HTM/STB/factsheet/2006.1

5. Gayle H: An overview of the global HIV/AIDS epidemic, with a focus on the United States. AIDS 2000; 14 (suppl.2): S8-S17

6. Thomas D: Hepatitis $\mathrm{C}$ and Human Immunodeficiency Virus Infection. Hepatology 2002; 36: S201-S209.

7. Contoreggi C, Rexroad VE, Lange WR: Current management of infectious complications in the injecting drug user. J Subs Abuse Treatment 1998; 15(2): 95-106.
8. Office of National Drug Policy: The Economic Costs of Drug Abuse in the United States: 19922002. Washington, DC: Executive Office of the President (Publication No. 207303). 2004.

9. American Diabetes Association. Economic costs of diabetes in the US in 2002. Diabetes Care 2003; 26: 917-932.

10. American Cancer Society. Cancer costs, Cancer Society, 2007.

11. Gold MS: Clinical aspects of substance abuse: A comprehensive text book, $3^{\text {rd }}$ Edition, Lewinson, ed. Baltimore, Wilkinson and Willey, 1997.

12. Ren S, Tong W, Lai H, Osman NF, Pannu H, Lai S: Effect of long-term cocaine use on regional left ventricular function as determined by magnetic resonance imaging. Am J Cardiol 2006 Apr 1;97(7):1085-8.

13. Lai S, Lima JA, Lai H, Vlahov D, Celentano D, Tong W, Bartlett JG, Margolick J, Fishman EK: Human immunodeficiency virus 1 infection, cocaine, and coronary calcification. Arch Intern Med 2005; 165(6):690-5.

14. Nair MP, Schwartz SA, Mahajan SD, Tsiao C, Chawda RP, Whitney R, Don Sykes BB, Hewitt R: Drug abuse and neuropathogenesis of HIV infection: role of DC-SIGN and IDO. J Neuroimmunol 2004; 157(1-2): 56-60.

15. do Samiero Fania M, Sampaio S, Fania V, Carvalho E: Nephropathy associated with heroin abuse in Caucasian patients. Nephron Dial Transplant 2003; 113: 2308-2313.

16. Khalsa JH, Genser S, Francis H, Martin B: Clinical consequences of marijuana. J Clin Pharmacol 2002; 42(11): 7s-11s.

17. Cao Y, Qin L, Zhang L, Safrit J, Ho DD: Virologic and immunologic characterization of long-term survivors of human immunodeficiency virus type 1 infection. New Engl J Medicine 1995; 332: 201208.

18. Gunn RA, Murray PJ, Ackers ML, Hardison WG, Margolis HS: Screening for chronic hepatitis B and $\mathrm{C}$ virus infections in an urban sexually transmitted disease clinic: rationale for integrating services. Sex Transm Dis 2001; 8(3): 166-70.

19. Garfein RS, Doherty MC, Monterroso ER, Thomas DL, Nelson KE, Vlahov D. Prevalence and incidence of hepatitis $C$ virus infection among young adult injection drug users, $\mathrm{J}$ Acquir Immune Defic Syndr Hum Retrovirol 1998; 18(suppl 1): 1119.

20. Law MG. Modelling the hepatitis $\mathrm{C}$ virus epidemic in Australia. Hepatitis C Virus Projections Working Group, J Gastroenterol Hepatol 1999; 14: 1100-1107 
21. MacDonald MA, Wodak AD, Dolan KA, van Beek I, Cunningham PH, Kaldor JM. Hepatitis C virus antibody prevalence among injecting drug users at selected needle and syringe programs in Australia, 1995-1997. Collaboration of Australian NSPs, Med J Aust 2000; 172: 57-61

22. Quaglio G, Lugoboni F, Pajusco B. Factors associated with hepatitis $\mathrm{C}$ virus infection in injection and noninjection drug users in Italy, Clin Infect Dis 2003, 37: 33-40

23. Thomas DL, Vlahov D, Solomon L. Correlates of hepatitis $\mathrm{C}$ virus infections among injection drug users, Medicine (Baltimore), 1995; 4: 212-220

24. United Nations AIDS (UNAIDS). 2006 Report on the global epidemic of AIDS: Executive Summary; UNAIDS/06-20E, English, ISBN 929-1735-116, Joint United Nations Programme on HIV/AIDS/WHO.

25. Dore GJ, Law M, MacDonald M, Kaldor JM. Epidemiology of hepatitis $\mathrm{C}$ virus infection in Australia. J Clin Virol 2003; 26(2): 171-84.

26. Sullivan LE, Fiellin DA: Hepatitis C and HIV infections: implications for clinical care in injection drug users. Am J Addict 2004; 13(1): 120.

27. Howard AA, Klein RS, Schoenbaum EE: Association of hepatitis $\mathrm{C}$ infection and antiretroviral use with diabetes mellitus in drug users. Clin Infect Dis 2003; 36(10): 1318-23.

28. Balasubramanian A, Koziel M, Groopman JE, Ganju RK: Molecular mechanisms of hepatic injury in co-infection with hepatitis $\mathrm{C}$ and human immunodeficiency virus. Clin Infect Dis 2005; 41 (suppl 1): s32-s37

29. Steinbrook R. Tuberculosis and HIV in India. N Engl J Med 2007; 356(12):1198-9

30. Centers for Disease Control and Prevention (CDC). Trends in Tuberculosis in the United States, 2006, Morbidity and Mortality Weekly Report (MMWR), 2007; 56 (11): 245-272.

31. Selwyn PA, Alcabes P, Hartel D, Buono D, Schoenbaum EE, Klein RS, Davenny K, Friedland $\mathrm{GH}$ : Clinical manifestations and predictors of disease progression in drug users with human immunodeficiency virus infection. N Engl J Med 1992; 327(24):1697-703.

32. Selwyn PA, Hartel D, Lewis VA, Schoenbaum EE, Vermund SH, Klein RS, Walker AT, Friedland $\mathrm{GH}$ : A prospective study of the risk of tuberculosis among intravenous drug users with human immunodeficiency virus infection. N Engl J Med 1989; 320(9):545-50.

33. Baum MK: Role of micronutrients in HIV-infected intravenous drug users. J Acquir Immune Defic Syndr 2000; 25 (Suppl 1): S49-52.
34. Hurwitz BE, Klaus JR, Llabre MM, Gonzalez A, Lawrence PJ, Maher KJ, Greeson JM, Baum MK, Shor-Posner G, Skyler JS, Schneiderman N: Suppression of human immunodeficiency virus type 1 viral load with selenium supplementation: a randomized controlled trial. Arch Intern Med 2007; 167(2):148-54.

35. National Institutes of Health Consensus Development Conference Statement. Management of hepatitis C: 2002. Bethesda, Md: National Institutes of Health; June 10-12, 2002.

36. Rosenberg S, Goodman L, Osher F, et al.: Prevalence of HIV, hepatitis B, and hepatitis C in people with severe mental illness. Am J Public Health 2001; 91 (1): 31-7

37. Angelino AF, Treisman GJ: Evidence-informed assessment and treatment of depression in $\mathrm{HCV}$ and interferon-treated patients. Int Rev Psychiatry 2005; 17(6): 471-6

38. Safdar K, Schiff ER: Alcohol and hepatitis C. Semin Liver Dis 2004; 24 (3): 305-15

39. Huckans MS, Loftis JM, Blackwell AD, Linke A, Hauser P: Interferon alpha therapy for hepatitis C: treatment completion and response rates among patients with substance use disorders. Subst Abuse Treat Prev Policy 2007; 12: 2-4

40. Sylvestre DL: Treating hepatitis $C$ virus infection in substance users. Clin Infect Dis 2005; 40 (Suppl 5): S321-4

41. Himelhock S, Moore RD, TreismanGJ, Gebo KA: Does the Presence of a Current Psychiatric Disorder in AIDS Patients Affect the Initiation of Antiretroviral Treatment and Duration of Therapy?. J Acquir Immune Defic Syndr 2004; 37 (4): 1457-63.

42. Treisman GJ, Angelino AF, Hutton HH: Psychiatric Issues in the Management of Patients with HIV Infection. JAMA 2001: 286 (22) 28572864.

43. Puzantian T: Central nervous system adverse effects with efavirenz: case report and review. Pharmacotherapy 2002; 22(7): 930-3.

44. Himelhoch S, Medoff DR: Efficacy of antidepressant medication among HIV-positive individuals with depression: a systematic review and meta-analysis. AIDS Patient Care STDS 2005; 19(12): 813-22.

45. Celentano DD, Galai N, Sethi AK, Shah NG, Strathdee SA, Vlahov D, Gallant JE: Time to initiating highly active antiretroviral therapy among HIV-infected drug users. AIDS 15: 1707$1715,2001$.

46. Strathdee SA, Palepu A, Cornelisse PG, Yip B, O'Shaughnessy MV, Montaner JS, Schecter MT, Hogg RS: Barriers to use of free antiretroviral therapy in injection drug users. JAMA 280: 547$549,1998$. 
47. Lucas GM, Cheever LW, Chaisson RE, Moore RD: Detrimental effects of continued illicit drug use on the treatment of HIV infections. J Acquir Immune Defic Syndr 2001; 27: 251-259.

48. Gifford AL, Bormann JE, Shively MJ, Wright BC, Richman DD, Bozette SA: Predictors of selfreported adherence and plasma HIV concentrations in patients on multidrug antiretroviral regimens. $\mathrm{J}$ Acquir Immune Defic Syndr 2000; 23: 386-395.

49. McCance-Katz EF: Treatment of opioid dependence and HIV/HCV co-infection in opioid dependent patients: the importance of drug interactions between opioids and antiretroviral medications. Clin Inf Dis 2005; 41: S89-S95.

50. Arnsten JH, Demas PA, Grant RW, GourevitchMN, Farzadegan H, Howard AA, Schoenbaum EE: Impact of active drug use on antiretroviral therapy adherence and viral suppression in HIV-infected drug users. J Gen Intern Med 17: 377-381, 2002.

51. McCance-Katz EF, Jatlow P, Rainey P, Friedland $\mathrm{G}$ : Methadone effects on zidovudine (AZT) disposition (ACTG 262). J Acquir Immune Defic Syn Hum Retrovirol 1998; 18: 435-443.

52. McCance-Katz EF, Rainey PM, Friedland G, Kosten TR, Jatlow P: Effect of opioid dependence pharmacotherapies on zidovudine disposition. Am J Addictions 2001; 10: 296-307.

53. McCance-Katz EF, Moody DE, Morse G, Pade P, Friedland G, Baker J, Alvanzo A, Smith P, Abayomi O, Jatlow P, Rainey PM: Interactions Between Buprenorphine and antiretrovirals I: NonNucleoside Reverse Transcriptase Inhibitors I: Efavirenz and Delavirdine, Clinical Infectious Diseases 2006; 43 (Suppl 4): S224-34.

54. McCance-Katz EF, Moody DE, Morse G, Pade P, Friedland G, Baker J, Alvanzo A, Smith P, Jatlow P, Rainey PM: Interactions between buprenorphine and antiretrovirals II: Protease inhibitors, nelfinavir, lopinavir/ritonavir, or ritonavir. Clin Inf Dis 2006; 43 (Suppl 4): S235-46.

55. McCance-Katz EF, Gourevitch MN, Arnsten J, Sarlo J, Rainey P, Jatlow P: Modified Directly Observed Therapy (MDOT) For Injection Drug Users With HIV Disease. Am J Addict 2002; 11: 271-278.

56. Pawlotsky JM, Gish RG. Future therapies for hepatitis C. Antivir Ther. 2006;11(4):397-408.
57. Nelson D, Rustgi V, Balan V, et al. A phase 2 study of albuferon in combination with ribavirin in non-responders to prior interferon therapy for chronic hepatitis C. Program and abstracts of the 56th Annual Meeting of the American Association for the Study of Liver Diseases (AASLD); November 11-15, 2005; San Francisco, California. Abstract 204; Bacon B, Regev A, Ghalib R, et al. Use of daily interferon alfacon-1 (Infergen) plus ribavirin in patients infected with hepatitis $\mathrm{C}$ (HCV) who are nonresponders to previous pegylated interferon plus ribavirin therapy: 24week and end of treatment data from the DIRECT trial. Program and abstracts of the 57th Annual Meeting of the AASLD; October 27-31, 2006; Boston, Massachusetts. Abstract LB18.

58. Bacon B, McHutchison J, Gordon S et al. Safety, pharmacodynamic (PD) and pharmacokinetic (PK) profiles of CPG 10101 (Actilonä), a novel TLR9 agonist: comparison in normal volunteers and HCV infected individuals. Programs and abstracts of Digestive Disease Week; May 14-19, 2005; Chicago, Illinois. Abstract 525.

59. McHutchison J, Bacon BR, Gordon SC, et al. Early viral response to CPG 10101, in combination with pegylated interferon and/or ribavirin, in chronic HCV genotype 1 infected patients with prior relapse response. Program and abstracts of the 56th Annual Meeting of the AASLD; November 11-15, 2005; San Francisco, California. Abstract 730.

60. Sekar V, De Meyer S, Vangeneugden T, et al. Pharmacokinetic/pharmacodynamic analyses of TMC114 in the POWER 1 and POWER 2 trials in treatment-experienced HIV-infected patients. Program and abstracts of the 13th Conference on Retroviruses and Opportunistic Infections; February 5-8, 2006; Denver, Colorado. Abstract $639 b$.

61. http://www.panacos.com/product_2.htm Accessed 4 February 2007 Final: 5/28/2007/Khalsa 